\title{
How informed is consent? Understanding of pictorial and verbal probability information by medical inpatients
}

\author{
R Fuller, N Dudley, J Blacktop
}

Postgrad Med J 2002;78:543-544

Understanding probability information about treatment risks and benefits is a vital component of patients' decision making capacity. This study demonstrates extensive misunderstanding of verbal descriptions of probability by medical inpatients of all ages, questioning the extent of their capacity for giving informed consent. Pictorial descriptions of probability were well understood, suggesting their adoption into clinical practice.

n the modern National Health Service, doctors and patients are increasingly encouraged to work together in a partnership role, whereby patients make informed choices about their medical care, and give informed consent to proposed treatments. The current Secretary of State for Health, Alan Milburn, indicated this in a recent speech to the New Health Network, stating that patients "have a right to be involved in decisions about their own care". ${ }^{1}$ The Department of Health has recently published a comprehensive guide to the consent process. $^{2}$ In order to give valid informed consent, it is necessary to possess the capacity to consent-an individual must be able to understand and retain information regarding the proposed treatment, its risks and benefits, and the likely consequences of declining treatment. ${ }^{3}$

Consent may only be considered to be truly valid once a person has weighed the risks and benefits of accepting or declining treatment and reached an informed choice. It follows that understanding probability information in relation to treatment risks and benefits is a fundamental component of this process. We have previously found that medical inpatients aged $\geqslant 75$ years are confused by different expressions of probability, and both overestimate and underestimate verbal descriptions of probability. ${ }^{4}$ Such misunderstanding could impact significantly on the capacity to make an informed decision and give valid consent. This study aimed to complement these findings, and to assess whether age itself was a factor in understanding probability information by inpatients.

\section{Key points}

- Developing doctor-patient partnerships and patient centred decision making are key themes within the NHS.

- Capacity to consent and make treatment decisions implies informed choice through an understanding of the probabilities of good and adverse outcomes of treatments.

- Patients often misunderstand probability information, and this can have serious impact on decision making, with patients incorrectly accepting or declining treatment risks due to misunderstanding.

- Pictorial data is of benefit in helping explain probability to patients, and merits introduction into clinical practice.

\section{PATIENTS AND METHODS}

Over a four month period, 103 medical inpatients were assessed by one of the researchers (RF) at Huddersfield Royal Infirmary. Of these, 19 were discharged before being seen, and 28 were excluded due to serious or terminal illness, cognitive impairment, or significant audiovisual impairment. Of the remaining 56, $42(75 \%)$ consented to participate in the study-a researcher administered questionnaire examining probability understanding. This used a crowd figure pictogram (fig l) to visually represent probabilities, in addition to allowing participants to demonstrate their understanding of verbal descriptions of fractional and percentage probability. The range of correct responses for this group (median age 52 years) is compared against those of 50 older inpatients recruited previously (median age 82 years); see table 1 .

Although younger subjects generally outperformed their older counterparts, pictorial representation of probability was well understood by both groups. In contrast, understanding of verbal percentage probability was generally less well understood, and other than understanding the concept of one in 100, both groups made a large number of errors when

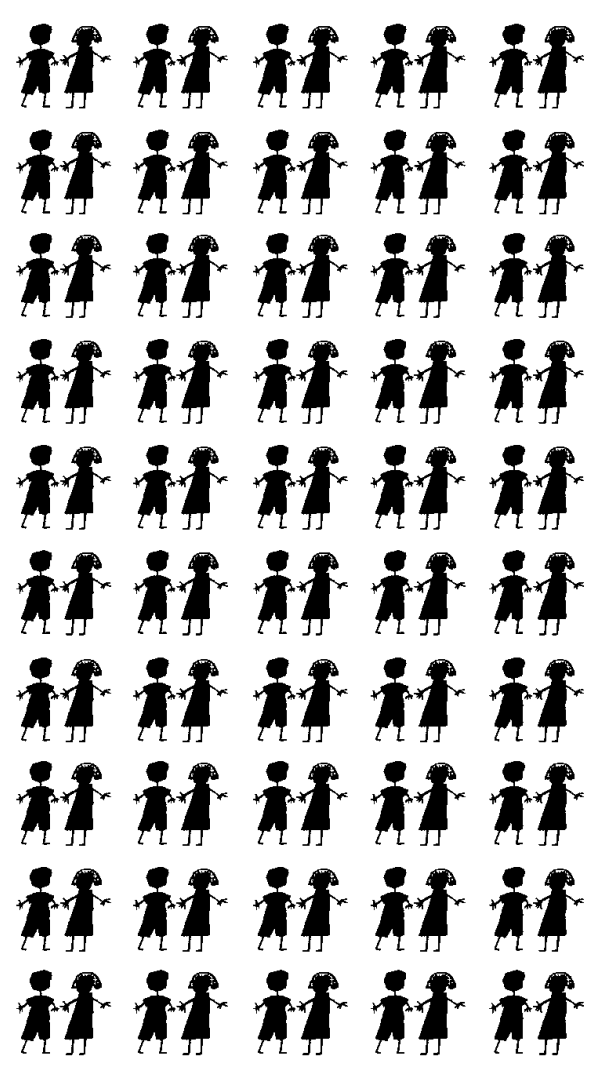

Figure 1 Crowd figure pictogram. 


\begin{tabular}{|c|c|c|c|c|c|c|}
\hline & \multicolumn{2}{|c|}{ Pictorial } & \multicolumn{2}{|c|}{ Verbal (\%) } & \multicolumn{2}{|c|}{ Verbal (fractional) } \\
\hline & $24-65$ & $>75$ & $24-65$ & $>75$ & $24-65$ & $>75$ \\
\hline 1 in $5(20 \%)$ & 90 & 74 & 93 & 74 & 48 & 38 \\
\hline 1 in $2(50 \%)$ & 98 & 92 & 98 & 98 & 60 & 50 \\
\hline 3 in $4(75 \%)$ & 93 & 90 & 88 & 63 & 55 & 48 \\
\hline 1 in $10(10 \%)$ & 95 & 82 & 93 & 77 & 81 & 79 \\
\hline 1 in $100(1 \%)$ & 100 & 99 & 93 & 71 & 95 & 78 \\
\hline 1 in $20(5 \%)$ & 90 & 70 & 86 & 51 & 52 & 39 \\
\hline
\end{tabular}

interpreting verbal descriptions of fractional probabilities (for example, one in five). Analysis of incorrect answers showed wide variations in overestimation and underestimation of probabilities irrespective of age. Many patients were confused by different expressions of probability: 15 (16\%) of the 92 patients thought one in five and 5\% were identical, while 25 (27\%) confused one in 20 and $20 \%$. A $75 \%$ probability was misrepresented by answers ranging between $6 \%$ and $90 \%$.

\section{DISCUSSION}

Many previous studies and reviews have examined the methods clinicians use to communicate information to patient, with some demonstrating complex usage of multiple expressions of probability information. ${ }^{5}$ We have shown that irrespective of age, all patients have the potential to misinterpret numerical probability information, and this may have a serious impact upon decision making and informed consent. For example, quoting a risk of death of one in five (that is 20\%) might be interpreted by a patient as $5 \%$, altering their decision to undergo treatment with potentially fatal consequences. Similarly, a one in 20 risk interpreted as $20 \%$ might dissuade a patient from choosing a potentially beneficial intervention.

Given that one of the key elements of capacity for consent involves understanding probability information, the extent of misunderstanding seen in this study casts doubt on the capacity of patients of all ages. The implications for informed consent are widespread, both in seeking formal consent for interventions, as well as discussions about treatment or resuscitation. We suggest that the apparent benefits of pictorial representation of probability merit introduction into clinical practice, in order to optimise capacity and to attempt to enable patients to exercise their right to be involved in decisions about their own care.

\section{Authors' affiliations}

R Fuller, N Dudley, Elderly Services, St James's Hospital, Leeds LS7 9TF, UK

J Blacktop, School of Computing and Mathematics, University of Huddersfield, Huddersfield

Correspondence to: Dr Fuller; Ftworf@aol.com

Submitted 17 May 2002

Accepted 29 May 2002

\section{REFERENCES}

1 Ministerial Speeches. Redefining the national health services. Speech by Rt Hon Alan Milburn MP, Secretary of State for Health, to the New Health Network, 15 January 2002 (www.doh.gov.uk/ jan2002milburnnhn. htm

2 Department of Health. Reference guide to consent for examination or treatment. London: Department of Health, 2001.

3 Hewson B. The law on managing patients who deliberately harm themselves and refuse treatment. BM 1999;319:905-7.

4 Fuller R, Dudley N, Blacktop J. Risk communication and older people-understanding of probability and risk information by medical inpatient aged 75 years and older. Age Ageing 2001;30:473-5.

5 Makoul G, Arnston P, Schofield T. Health promotion in primary care; physician-patient communication and decision making about prescription medication. Soc Sci Med 1995;41:1241-54. 